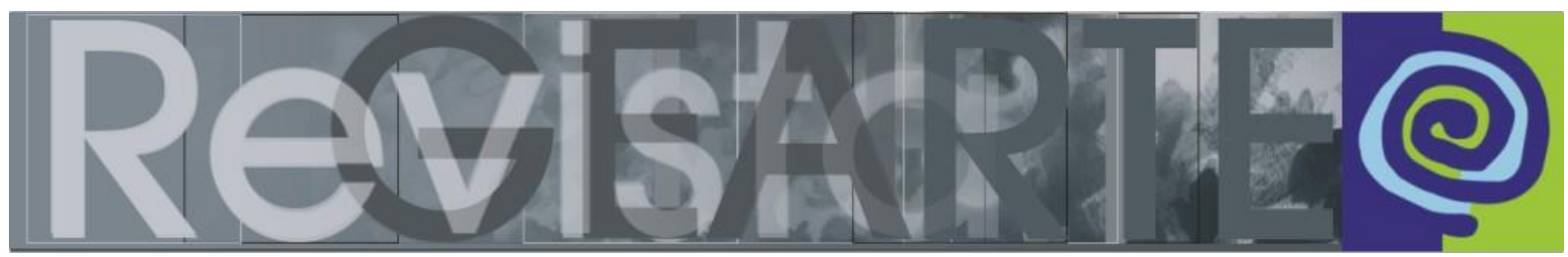

e-ISSN 2357-9854

\title{
Narrativas emergentes: a história de Luciana Lealdina de Araújo na produção de arte urbana
}

\author{
Larissa Patron Chaves (Universidade Federal \\ de Pelotas - UFPEL, Pelotas/RS, Brasil)
}

Thiago Madruga (Universidade Federal de Pelotas - UFPEL, Pelotas/RS, Brasil)

\begin{abstract}
RESUMO - Narrativas emergentes: a história de Luciana Lealdina de Araújo na produção de arte urbana - Este artigo objetiva refletir a respeito da produção de arte como dispositivo de discussão para a problemática da invisibilidade negra no Rio Grande do Sul, sua implicância na (re)construção de uma identidade em meio a questões políticas e sociais contemporâneas. Propomos através da arte contemporânea, uma narrativa mais pluralizada que a inclua histórias da população negra, muitas vezes marginalizadas ou registradas de forma superficial na historiografia local das cidades gaúchas. Nesse sentido, propomos apresentar como primeira narrativa a representação de Luciana Lealdina de Araújo, ex escrava na cidade de Pelotas no século XIX, cuja história fora marcada pela trajetória ligada a benemerência e religiosidade. Sua história possibilita o levantamento de questões sobre o contexto social em que viveu, sobre a dificuldade como mulher negra no conseguir apoio para criar uma instituição para meninas órfãs, e sobre a visibilidade de sua memória nos dias de hoje. Acreditamos que a arte urbana promove o encontro de várias culturas, desperta para a reflexão entre arte e política, uma vez que atua como fator que dialoga com as diferentes cidades existentes em um mesmo espaço e, dessa forma, no devir que acompanha cada proposta de Arte. Esta pesquisa, ligada à dissertação de mestrado em Artes Visuais da Universidade Federal de Pelotas, busca promover o debate multidisciplinar ente Arte e Política, tendo a intervenção urbana como ponto circunstancial para a discussão sobre o tema proposto.
\end{abstract}

PALAVRAS-CHAVE

Luciana-Araújo. Intervenção-urbana. Arte-política. Narrativas-negras.

ABSTRACT - Emerging narratives: the history of Luciana Lealdina de Araújo in the production of urban art - This article aims to reflect about the production of art as a discussion device for the problem of black invisibility in Rio Grande do Sul, its implication in (re) building an identity in the midst of contemporary political and social issues. We propose through contemporary art a more pluralized narrative that includes stories of the black population, often marginalized or recorded in a superficial way in the local historiography of the south cities of Brazil. In this sense, we propose to present as a first narrative the representation of Luciana Lealdina de Araújo, former slave in the city of Pelotas in the nineteenth century, whose history was marked by the trajectory linked to merit and religiosity. Her story makes it possible to raise questions about the social context in which she lived, about the difficulty as a black woman in getting support to create an institution for orphaned girls, and on the visibility of her memory today. We believe that urban art promotes the encounter of several cultures, awakens to the reflection between art and politics, since it acts as a factor that dialogues with the different cities existing in the same space and, in this way, in the becoming that accompanies each proposal of Art. This research, linked to the Master's thesis in Visual Arts of the Federal University of Pelotas, seeks to promote the multidisciplinary discussion between Art and Politics, with urban intervention as a circumstantial point for discussion on the proposed theme.

KEYWORDS

Luciana-Araújo. Urban-intervention. Political-art. Black-narratives.

CHAVES, Larissa Patron; MADRUGA, Thiago. Narrativas emergentes:

a história de Luciana Lealdina de Araújo na produção de arte urbana. 


\section{Introdução}

O que fazer quando a narrativa vigente da cultura em que você está inserido Ihe excluí? Como adquirir noção de pertencimento em uma cultura onde o discurso ideológico responsável por produzir o sentido das identidades oculta referências sobre seu povo, com base em um discurso ainda de cunho racialista? Como lidar com a crise de identidade cultural, gerada por esse tipo de fragmentação?

Em função da ausência de referências, sempre tive dificuldade em unificar minha identidade cultural, fragmentada entre ser negro e ser gaúcho. A cultura do Rio Grande do Sul tem como característica recorrente uma grande valorização da figura do imigrante europeu, vindo de países como Portugal, Itália e Alemanha para colonizar o Estado. Inclusive, projetando ainda hoje a imagem de um estado eurocêntrico, em um país bastante marcado pelos processos do multiculturalismo e da miscigenação.

Entretanto, essa mesma cultura atribui à população negra e suas contribuições, uma condição problemática de invisibilidade. Presente em segmentos que vão das tradições e da arte, até a narrativa histórica vigente, compartilhada em espaços educacionais. Nesta perspectiva, podemos identificar nessa condição de invisibilidade, o intuito de um apagamento histórico. De um projeto de embranquecimento cultural no Rio Grande do Sul, desenhado para desvencilhar a imagem do gaúcho, da figura do negro.

Este artigo promove reflexão a respeito da produção de arte como dispositivo de discussão para a problemática da invisibilidade negra no Rio Grande do Sul, sua implicância na (re) construção de uma identidade em meio a questões políticas e sociais contemporâneas. Propomos através da arte contemporânea, uma narrativa mais pluralizada que inclua histórias da população negra, muitas vezes marginalizadas ou pouco conhecidas pela população em geral. A partir da produção que enfoca intervenções urbanas, a pesquisa busca compartilhar narrativas negras gaúchas no espaço público, no intuito de rememorar sua participação e suas contribuições para a formação do estado e sua cultura. Um esforço para abordar a história do Rio Grande do Sul a partir de uma perspectiva mais pluralizada, onde a população negra possa se sentir pertencente também. Estas intervenções tiveram 
como ponto de partida a história de Luciana Lealdina de Araújo, ex escrava na cidade de Pelotas no século XIX, cuja história fora marcada pela trajetória ligada a benemerência e religiosidade.

\section{Luciana Lealdina de Araújo}

Luciana Lealdina de Araújo é descrita como uma mulher alta, negra de pele retinta e filha de uma escrava, nascida na cidade de Porto Alegre em 13 de Junho de 1870, mas que posteriormente muda-se para a cidade de Pelotas. Luciana sensibilizava-se com realidade de diversas meninas negras e órfãs que estavam desabrigadas e não tinham para onde ir. Após contrair tuberculose, Luciana de Araújo faz uma promessa a São Benedito, dizendo que em caso de cura, construiria um lugar para abrigar estas meninas.

Segundo a pesquisadora Jeane Caldeira, o relato de Irmã Assunta afirma que "Luciana após ter ficado curada da tuberculose se instalou em uma casa bem "pobrezinha" em Pelotas, juntamente com seis meninas na qual ela ensinava tudo" (2014, p.147). Apesar das dificuldades da época, Luciana de Araújo era alfabetizada e passava o ensino adiante, além de também exercer o ofício de quitandeira. E após conseguir o auxílio de algumas pessoas da cidade, conseguiu a realização de dois feitos incríveis, tendo em vista sua condição como filha de escravos em uma cidade do interior do Estado no final do século XIX. Destacamos que essa questão social deve ser problematizada, uma vez que se trata ainda, na primeira República, de uma sociedade oligárquica e extremamente fechada quanto a seu regramento social. Quando se tornou a principal fundadora do Asilo de Órfãs São Benedito na cidade de Pelotas em 1901, e do Orfanato São Benedito na cidade de Bagé em 1909, fora de fato um acontecimento inédito. Desde então, abrigou e alfabetizou diversas meninas desfavorecidas econômica e socialmente.

\section{Processos de criação poética}

A maneira utilizada para contar a história de Luciana Lealdina de Araújo em Pelotas, e compartilha-la com o maior número de pessoas possível, deu-se através da elaboração de uma produção artística pensada para ser posteriormente 
desdobrada em condição múltipla, em múltiplas mídias, para ocupar diversos espaços, tanto físicos, quanto virtuais. Pensando nisso, a primeira ação foi à realização de intervenções urbanas por meio da colagem de lambe-lambes ${ }^{1}$, servindo como um excelente dispositivo, através do qual poderia vir a propor uma experiência de partilha da sensível no espaço urbano. Segundo o pensamento de Jacques Rancière, podemos denominar:

\begin{abstract}
Partilha da sensível o sistema de evidências sensíveis que revela, ao mesmo tempo, a existência de um comum e dos recortes que nele definem lugares e partes respectivas. Uma partilha da sensível fixa portanto, ao mesmo tempo, um comum partilhado e partes exclusivas. Essa repartição das partes e dos lugares se funda numa partilha de espaços, tempos e tipos de atividade que determina propriamente a maneira como um comum se presta à participação e como uns e outras tomam parte nessa partilha (RANCIĖRE, 2005, p.15).
\end{abstract}

Para as intervenções urbanas que executo, penso que a proposta de partilha se dá, por incluir na esfera pública um signo iconográfico (atuante como uma interface para as minhas inquietações), a ser partilhado entre os observadores perceptivos, que mostrarem-se interessados em participar desse processo.

No processo de criação, também foi preciso pensar a respeito do quanto este trabalho necessitava fazer-se facilmente compreensível para as pessoas, sobretudo por se tratar de uma obra que seria exposta na esfera pública, em meio ao fluxo de transeuntes. Nesses casos, a leitura precisa ser fácil. Uma vez que hoje em dia, com o ritmo acelerado das cidades e até mesmo em função de fatores como a "insegurança pública", fica cada vez mais difícil para os transeuntes desacelerarem o passo para efetuarem processos de contemplação. Razão pela qual o cartaz precisa ser convidativo e a sua mensagem precisa ser objetiva.

Outra questão importante na busca para alcançar maior efetividade nas intervenções, correspondeu à importância de levar em consideração, durante seu planejamento, o tempo e o espaço em que o trabalho estaria sujeito. É importante destacar que a "Arte Urbana pode ser definida como uma arte contemporânea, de

1 A colagem de lambe-lambe consiste em uma ação, desenvolvida por meio de uma técnica de fixação de cartazes sobre alguma superfície, através de uma cola que na maioria das vezes é produzida a partir de uma mistura de farinha e água. Outra mistura bastante recorrente ocorre entre cola branca e água. 
cunho popular, que é feita em espaços externos da cidade, sobre o mobiliário urbano, sejam eles paredes, muros, placas e todo tipo de aparato de sinalização (FERREIRA, 2010, P.01)" É preciso pensar que, desde que a sociedade se pensa como sociedade, a Arte é expressão, é política, é forma de reflexão, de reivindicação, de poder. Logo, é preciso pensar em quem o trabalho pode atingir e como. Na relação destas pessoas com o espaço onde ocorrerá a ação. E inclusive, pensar eventuais respostas que as pessoas podem dar a partir da intervenção. Refletir sobre estas questões foi de suma importância para o planejamento das intervenções e para a composição do cartaz.

A princípio, pensei que a composição do cartaz havia se originado a partir de, pelo menos, dois processos simultâneos. A pesquisa histórica e o processo de criação da imagem. Entretanto, estes processos possuem uma relação intrínseca, ou seja, um complementa e potencializa o outro. A pesquisa histórica, conduzida a partir de uma série de leituras, me permitiu, para além de conhecer a história de Luciana de Araújo, entender um pouco mais sobre o contexto social em que ela viveu, durante o período de escravidão até algumas de suas implicações, no pós-abolição. Também possibilitou mapear alguns espaços específicos para a prática das intervenções, e encontrar tanto imagens, quanto fragmentos textuais que foram incorporados como elementos vitais para a composição da estética do cartaz. Já a elaboração do processo de criação da imagem, permitiu criar um dispositivo através do qual, poderia levar parte da história de Luciana de Araújo para o espaço urbano e assim compartilhar com as pessoas alguns aspectos da sua história e suas contribuições, deslocando sua narrativa para a arquitetura da cidade através dos lambes, ressignificando espaços e oferecendo eventuais oportunidades de diálogo.

Para a composição do cartaz, utilizou-se um retrato de Luciana de Araújo, que surge como elemento central, a fim de dar destaque a sua imagem, que aparece envolta por uma grande moldura dourada. Já a imagem de fundo a qual seu retrato se sobrepõe, apresenta a figura de diversas meninas. Esta imagem não foi escolhida por acaso, pois trata-se de um registro fotográfico realizado no Orfanato São Benedito localizado na cidade de Bagé. E segundo a pesquisadora Jeane dos Santos Caldeira (2014, p.153), esta "fotografia foi publicada na revista Illustração Pelotense de número 8, do ano de 1919". Provavelmente 10 anos após criação do orfanato. Ou seja, para 
além de mostrar as meninas que foram beneficiadas pelo trabalho de Luciana de Araújo, o fato desta imagem ter sido publicada, propõe reflexões a respeito do quanto seus esforços poderiam estar sendo reconhecidos por parte da população pelotense. Atualmente, a condição de visibilidade parece não ser mais a mesma, uma vez que, quase um século após a publicação dessa imagem, os esforços de Luciana Lealdina de Araújo parecem desconhecidos por grande parte da população de Pelotas.

Figura 1 - Cartaz Mãe Luciana (2018).

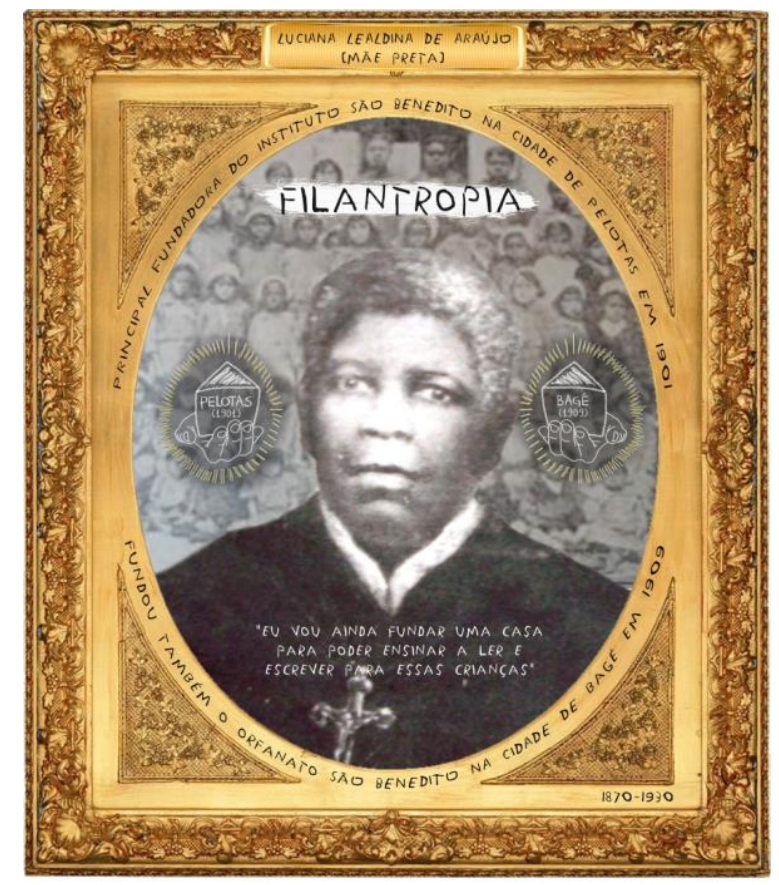

Fonte: Acervo Pessoal.

Além das fotografias, o cartaz também possui algumas informações textuais, adicionadas no intuito de complementar a imagem e potencializar a mensagem. Ao fornecer alguns dados capazes de contextualizar esta representação de Luciana de Araújo, o trabalho relaciona diretamente com a criação do Instituto e do Orfanato São Benedito, informando também o ano de fundação e a localização destas instituições. Essa mensagem é enfatizada pela presença das duas mãos desenhadas ao lado do rosto de Luciana de Araújo. No desenho, em cada mão há uma casa, representando ambas as instituições. Aqui, é interessante ressaltar que a mão estendida, por vezes é popularmente associada com a ideia de oferta, entrega e/ou doação, e por conta disto esta representação passou a ser vista como um símbolo de caridade ou 
filantropia, razão pela qual as instituições de benemerência entre o final século XIX e primeira metade do século XX foram criadas.

O desenho das mãos com a ilustração das casas, representando a entrega e as instituições fundadas por Luciana de Araújo, propõe ainda mais uma relação. Desta vez com a figura de Santa Efigênia, uma santa negra, frequentemente representada com uma casa em sua mão.

Figura 2 - Imagem de Santa Efigênia.

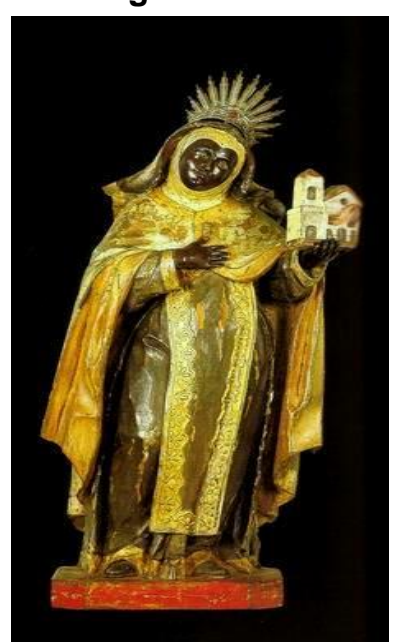

Fonte: Acervo Pessoal.

O historiador Anderson Oliveira ao descrever Santa Efigênia, através da narrativa de Frei José Pereira de Santana, afirma que

pertencia à nobreza. Princesa da Núbia, filha do rei Egyppo, teria se convertido ao cristianismo sendo batizada pelo apóstolo Mateus. Indiferente aos prazeres mundanos e aos requintes da corte, tornou-se religiosa fundando um convento. Após a sua conversão e a morte de seu pai, seu tio - Hitarco - teria usurpado o trono do herdeiro legítimo - Efrônio -, irmão de Efigênia, tentando desposá-la para consolidar o seu poder na Núbia. Efigênia teria se recusado a atender aos intentos do rei usurpador, despertando naquele uma profunda ira. Hitarco ordenou que fosse ateado fogo à habitação religiosa onde vivia Efigênia e as religiosas que ela liderava. O convento foi milagrosamente salvo por intercessão da santa (OLIVEIRA, 2006, p. 62).

Conforme vimos, a partir desta descrição, a casa que Santa Efigênia é vista carregando em suas representações, corresponde ao convento que ela criou. Esta casa costuma ser frequentemente representada em chamas, em alusão ao episódio do milagre da Santa, responsável por salvar o convento da tentativa de incêndio por parte de seu tio Hitarco. Já em outra versão popular de sua história, Santa Efigênia 
havia construído o convento para abrigar mulheres que compartilhassem de sua fé. $E$ sua representação sem as chamas estaria ligada de certa forma a sua vitória, na luta para proteger o convento e as pessoas que lá residiam, razão pela qual passou a ser vista como uma espécie de padroeira das pessoas sem moradia. Nesse ponto, podemos enxergar uma relação com a luta de Luciana de Araújo para fundar e manter instituições responsáveis por abrigar, alfabetizar e ensinar práticas religiosas a meninas desamparadas pelo Estado. Esforços representados pelo uso da palavra filantropia, que se destaca no cartaz, surgindo em cima do retrato de Mãe Luciana, afim de conduzir o observador a uma interpretação mais contextualizada da intervenção.

\section{A produção poética}

A elaboração das intervenções partiu primeiramente de um mapeamento de alguns lugares específicos na cidade de Pelotas, que dialogavam com a história de Luciana Lealdina de Araújo. A princípio as intervenções ocorreriam em 3 espaços. Primeiro no Instituto (antigo Asilo) São Benedito, fundado pela própria Luciana de Araújo e que apesar da sua saída em 1908, e das mudanças pelas quais passou ao decorrer dos seus 116 anos, ainda mantém seu funcionamento atrelado aos ideais de Mãe Luciana. E depois em outros 2 espaços que por levarem seu nome, ainda preservam indícios da sua história, mostrando como ela foi marcante na cidade de Pelotas, a Escola Municipal de Ensino Fundamental Luciana de Araújo e o Edifício Luciana de Araújo, onde o processo das intervenções foi iniciado. 
Figura 3 - Registro da intervenção com a colagem do Cartaz Mãe Luciana (2018).

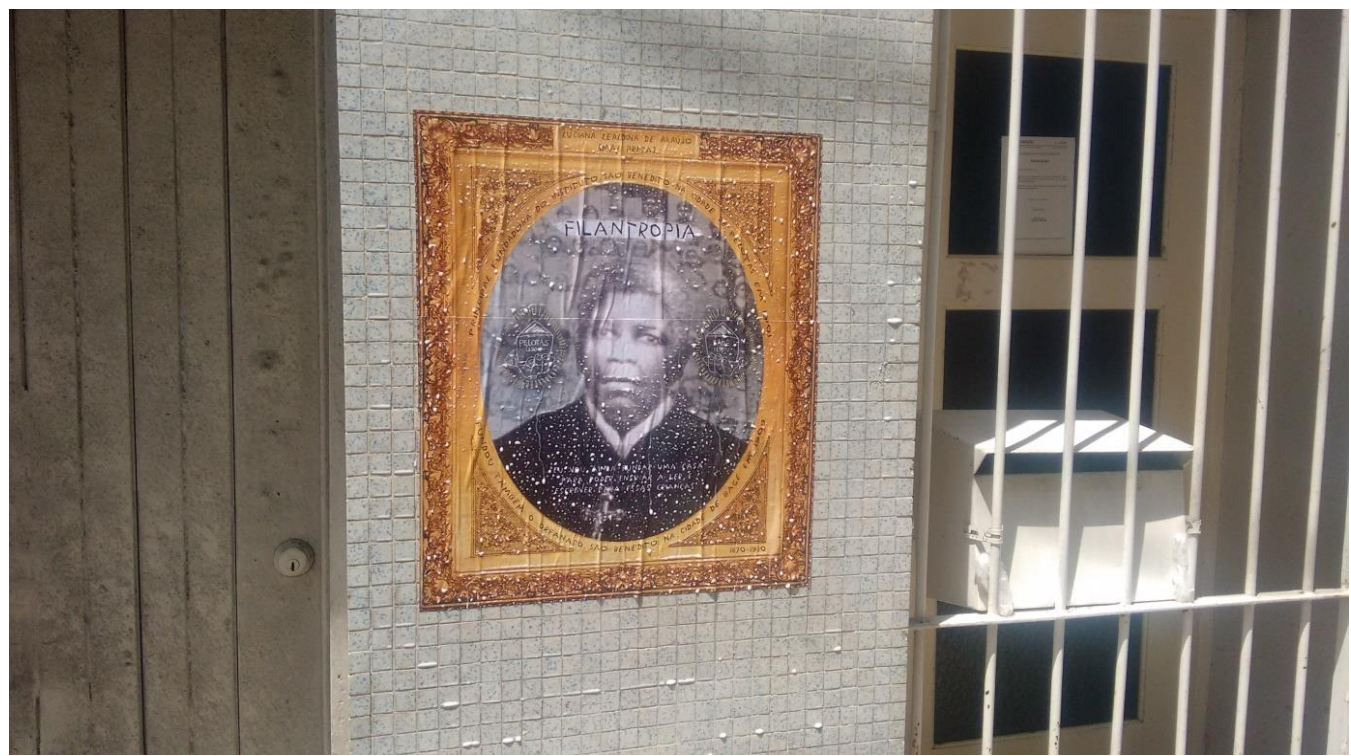

Fonte: Acervo Pessoal.

Figura 4 - Registro da intervenção com a colagem do Cartaz Mãe Luciana (2018).

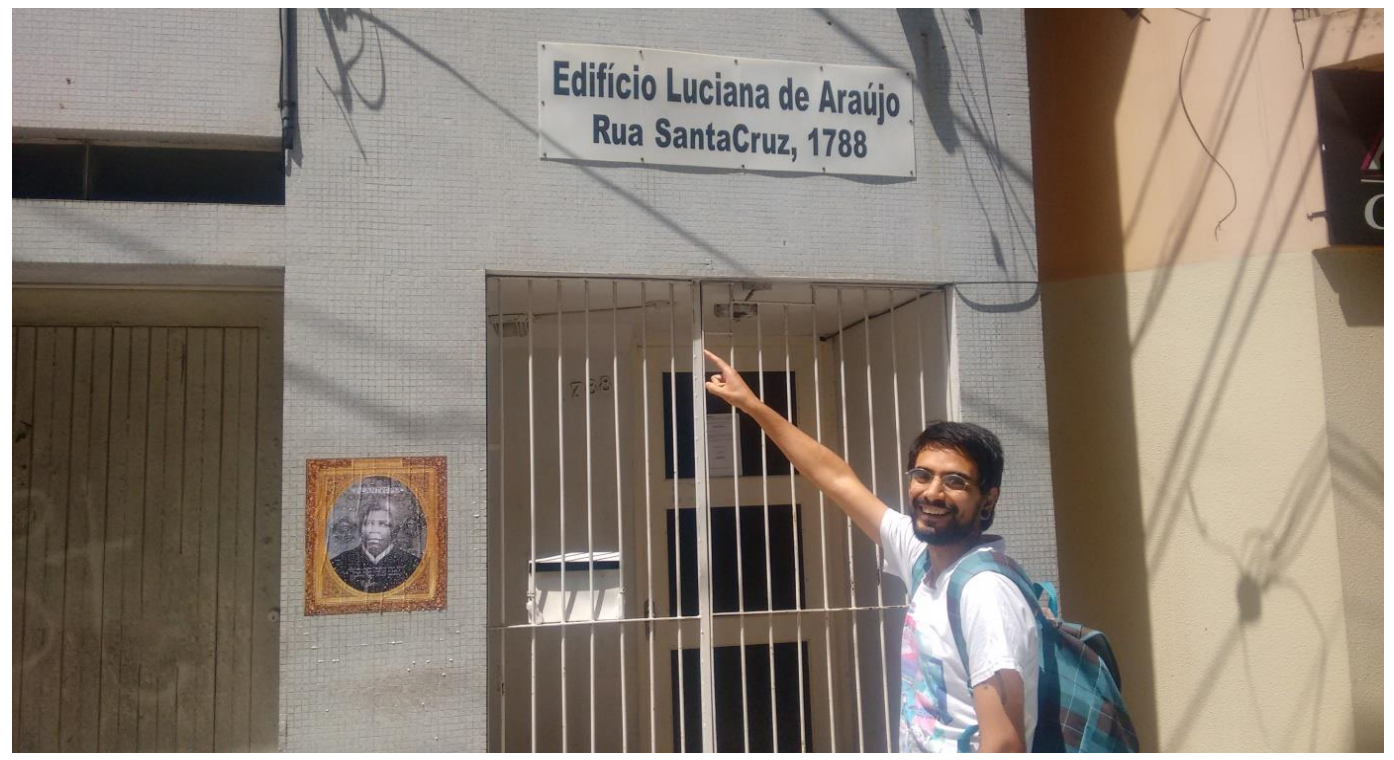

Fonte: Acervo Pessoal.

O interessante de colar neste espaço é a possibilidade aproximar a história de Luciana de Araújo das pessoas que vivem neste edifício, que podem não estar familiarizadas com a sua história. Apesar das suas contribuições, a história de Luciana de Araújo infelizmente parece cada vez mais esquecida pela memória local, razão que contribuiu para a elaboração de estratégias capazes de potencializar o alcance das intervenções. Tal fato, originou um novo mapeamento de espaços para a realização das próximas intervenções, desta vez escolhidos em função da quantidade pessoas 
que o atravessa ou ocupa, na intenção de atingir o maior grupo possível. Outra estratégia posta em prática, foi o compartilhamento de registros da colagem em redes sociais, acompanhados de um texto explicativo. A partilha no espaço virtual, constituise basicamente como uma interface para que esfera pública se projete dentro esfera privada. Ou seja, se na intervenção urbana o lambe-lambe é inserido na arquitetura da cidade, ressignifica espaços e propõe diálogos, ao mesmo tempo que opera no compartilhamento de imagens, onde o observador pode se deparar com o surgimento do trabalho no seu feed de notícias. Tudo isso, fomentou outro trabalho artístico, configurado como o primeiro volume da série de webzines ${ }^{2}$ do trabalho intitulado "Projeto Raízes: Mãe Luciana".

Figura 5 - Webzine Projeto Raízes Vol.1 Mãe Luciana (2018).

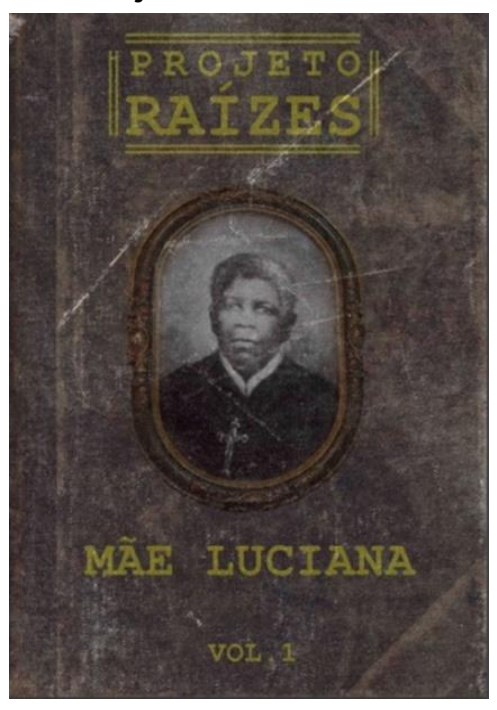

Fonte: Acervo Pessoal.

O projeto intitulado "Projeto Raízes", criado em 2018, foi estimulado pela tentativa de combater a condição de invisibilidade a qual a população negra e suas contribuições estão sujeitas na cultura gaúcha, através da contação de histórias. Apresentando a narrativa de Luciana de Araújo, através de um texto construído por rimas simples e objetivas, cuja disposição remete à estética presente na composição das letras de rap.

2 Livro de artista disponível em formato digital. 
Figura 6 - Webzine Projeto Raízes v.1 Mãe Luciana (2018).

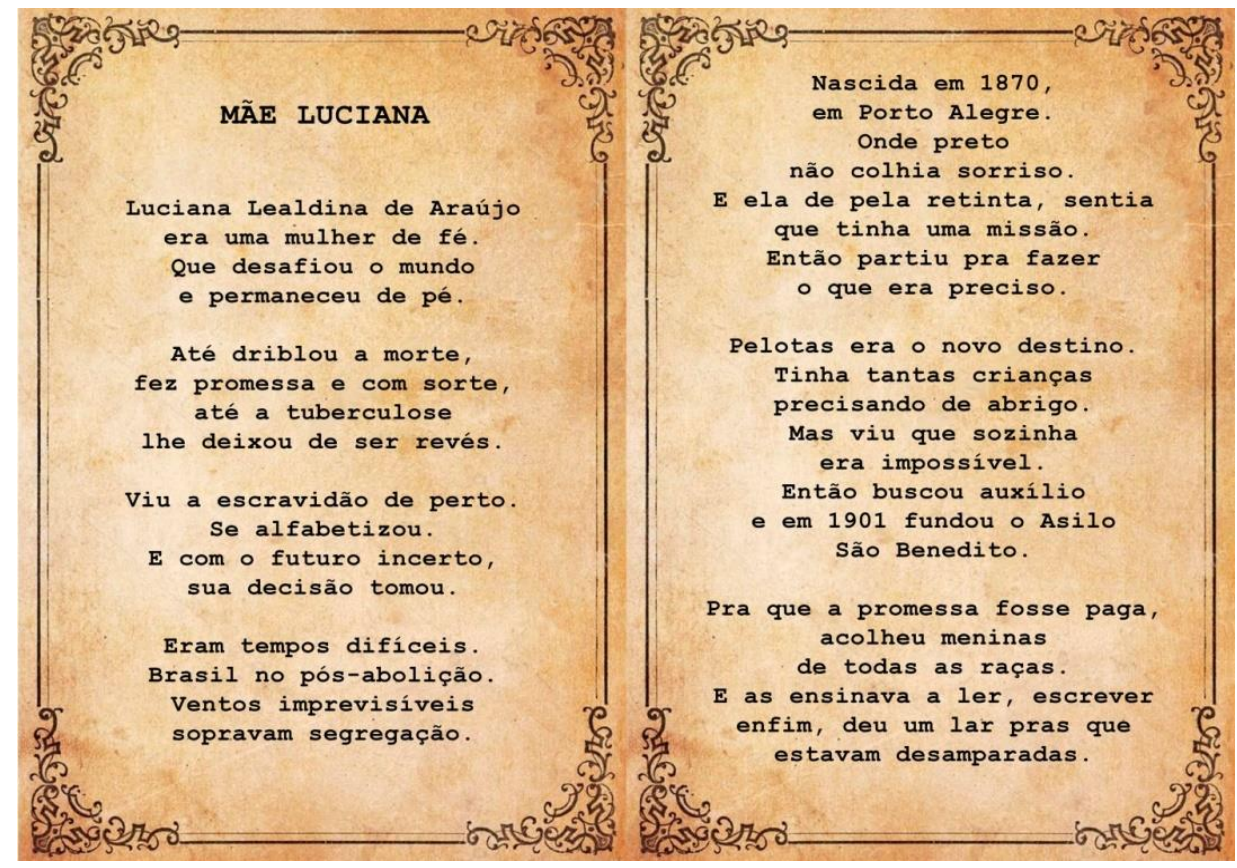

Fonte: Acervo Pessoal.

Ele surgiu a partir da necessidade de levar o trabalho realizado com as intervenções urbanas para outros espaços, inclusive virtuais, buscando expandir seu raio de atuação e facilitar o acesso à narrativa da Mãe Luciana. Assim, enquanto não há versão física, o webzine encontra-se disponível para leitura gratuita na plataforma digital Issuu. Da mesma forma, há também um planejamento para que após sua impressão, o primeiro volume do Projeto Raízes possa ser não apenas disponibilizado para quem demonstrar interesse em adquirir um exemplar, e sim para as escolas, como um recurso complementar para ministrar oficinas ou minicursos. A proposta do Projeto Raízes reforça a reflexão sobre a invisibilidade do negro no Rio Grande do Sul, uma vez que arte é um campo bastante propício para se trabalhar relações de sociabilidade, pensamento e fruição.

\section{Conclusão}

Ao darmos visibilidade para histórias como a de Luciana Lealdina de Araújo, temos a oportunidade de repensar questões referentes as contribuições da população negra para a história e cultura do Rio Grande do Sul. Apesar das condições difíceis do período de pós-abolição, ela conseguiu se tornar a principal fundadora de duas instituições responsáveis por abrigar e educar meninas, em municípios diferentes, tais 
como Pelotas e Bagé. Ressignificar a imagem de quem faz caridade, como uma educadora negra nascida no século XIX, é fundamental, ou seja, problematizar a sua imagem é devir da Arte, propondo uma reflexão a partir da sua potência. Arte é educação, arte é transformação de si, empoderamento. Certamente, reflexões sobre Arte, a partir da intervenção urbana, apontam à promoção de uma educação ética, cidadania, práticas de inclusão social, que não devem ser confundidas com assistencialismo, mas que devem ampliar a visão crítica sobre as questões do cotidiano na vida e na escola, no tempo e no espaço. E, principalmente, mais do que propiciar o acesso ao conhecimento e a informação, cabe a Arte o despertar crítico para a sensibilidade estética proporcionando uma nova forma de perceber o mundo. Compreendemos o fazer Arte e o refletir sobre Arte como uma difícil e prazerosa tarefa, como em Meira (2007), para escapar de uma realidade bruta e assim compreender uma outra forma de ver.

Essa intervenção nos traz uma história rica, que nos motiva a superar as limitações do nosso tempo e que também surge como um motivo para que outras histórias sejam contadas. A representação de Luciana é um dos exemplos que mostram o quanto nossa resistência está diretamente ligada as nossas raízes. Nossa força é ancestral, passada de geração a geração. E o conhecimento de nossa história, é uma herança que nos permite não apenas entender nosso lugar na história do Estado e reunir fragmentos que faltavam para construção de nossa identidade, como também nos permite abrir caminhos para as gerações futuras, da mesma forma que um dia eles foram abertos para nós.

\section{Referências}

BAKOS, M.M; BERND, Z. O negro no Rio Grande do Sul: consciência e trabalho. Porto Alegre: Universidade Federal do Rio Grande do Sul, 1991.

BOURRIAUD, N. Estética Relacional. São Paulo: Martins Fontes, 2009.

CALDEIRA, J. S. O Asilo de Órfãs Saõ Benedito em Pelotas - RS (as primeiras décadas do século XX): trajetória educativa-institucional. 2014. Dissertação (Mestrado em Educação) - Faculdade de Educação, Universidade Federal de Pelotas, Rio grande do Sul, 2014. Disponível em <http://repositorio.ufpel.edu.br/bitstream/ri/2809/5/O\%20Asilo\%20de\%20\%C3\%93rf\%C3\%A3s\%20S\% C3\%A30\%20Benedito\%20em\%20Pelotas.pdf > Acesso em: 21.02.2018.

HALL, S.M. A identidade cultural na pós modernidade. Rio de Janeiro: DP\&A,1992.

MEIRA, M. R. Educação estética, arte e cultura do cotidiano. In: PILLAR, A. D.(org.). A educação do olhar no ensino das artes. Porto Alegre: Mediação, 2001. 
OLIVEIRA, A. J. M. Devoção e Identidades: significados do culto de Santo Elesbão e Santa Efigênia no Rio de Janeiro e nas Minas Gerais no Setecentos. Topoi (Rio de Janeiro), v. 6, n.12, p. 60-115, 2006. Disponível em: <http://www.scielo.br/pdf/topoi/v7n12/2237-101X-topoi-7-12-00060.pdf>

RANCIÈRE, J. A Partilha do Sensível. São Paulo: Editora 34 Ltda, 2005.

FERREIRA, Maria Alice. Arte Urbana no Brasil: expressões da diversidade contemporânea. VIII Encontro Nacional de História da Mídia. Unicentro, Guarapuava, PR, 2010. Disponível em:Meus\%20documentos/Downloads/Arte\%20Urbana\%20no\%20Brasil\%20expressoes\%20da\%20div ersidade\%20contemporanea\%20(1).pdf

\section{Larissa Patron Chaves}

Professora Adjunta do Centro de Artes da Universidade Federal de Pelotas. Possui Graduação em Artes Visuais pela Universidade Federal de Pelotas (1995), Mestrado em História pela Pontifícia Universidade Católica do Rio Grande do Sul (2002), e Doutorado em História pela Universidade do Vale do Rio dos Sinos (2008), com período de atuação em estágio de doutoramento na Universidade do Porto (Portugal) entre os anos de 2005 e 2006. Atualmente é coordenadora adjunta do Mestrado em Artes Visuais, integra o corpo docente do Mestrado em História e o corpo docente da especialização em Artes - modalidade à distância - ambos da Universidade Federal de Pelotas. É representante da área de Linguística, Letras e Artes na Secretaria dos Conselhos - COCEPE - da Universidade Federal de Pelotas.

Email: larissapatron@gmail.com

Currículo: http://lattes.cnpq.br/3858201697400054

\section{Thiago Madruga}

Artista multimídia com prática em intervenção urbana. Graduado em Artes Visuais - Bacharelado com ênfase em Poéticas Visuais pela Universidade Federal do Rio Grande - FURG, no Rio Grande do Sul. Mestrando no programa PPGAV - UFPel na linha de pesquisa: Processos de criação e poéticas do cotidiano. Integra o grupo de pesquisa Núcleo de Estudos Afro Brasileiros e Indígenas, do(a) Universidade Federal do Rio Grande. Suas pesquisas orbitam a arte contemporânea, arte urbana, arte ativista e história e cultura afro-brasileira.

Email: thiagomadrugads@gmail.com

Currículo: http://lattes.cnpq.br/3957342925272088

Recebido em 31 de maio de 2018 Aceito em 16 de julho de 2018 